\title{
DOAÇÃO DE ÓRGÃOS: A EXPERIÊNCIA DOS PROFISSIONAIS DE SAÚDE
}

\author{
Organ donation: the experience of health care professionals
}

\author{
Isabela Castelli', Nayanne da Ponte Meneses², Áderson Luiz Costa Junior ${ }^{1}$
}

\section{RESUMO}

A partir da regulamentação do Sistema Nacional de Transplantes, com a criação das equipes de Comissão IntraHospitalar de Doação de Órgãos e Tecidos para Transplante (CIHDOTT), estruturou-se novo campo de atuação para profissionais de saúde. Neste, apresentam-se como tarefas: organizar o processo de captação e doação de órgãos; detectar pacientes que sejam classificados como potenciais doadores de órgãos e questionar a família do paciente sobre o desejo de doar os órgãos para transplante. Objetivo: Considerando-se que o trabalho em hospitais é potencialmente estressor e, no contexto acima descrito, agravado pelo contato direto com a morte e a finitude, entrevistou-se uma equipe de nove profissionais de saúde de um hospital público de Brasília, com intenção de compreender a experiência de trabalho. Método: Os profissionais de saúde foram convidados a participar do presente estudo embasado no método da entrevista semiestruturada. As entrevistas foram gravadas em áudio e transcritas na íntegra. Posteriormente, realizou-se análise de discurso com a elaboração de eixos temáticos. Resultados: No presente texto, destacam-se as seguintes categorias: carga emocional, considerações sobre a morte e foco no receptor. Conclusão: Os dados aqui discutidos, em conformidade com a literatura atual, ressaltam a necessidade de treinamento adequado dos profissionais de saúde integrantes de CIHDOTT, bem como a importância de espaços de escuta e troca entre pares.

Descritores: Obtenção de Tecidos e Órgãos; Morte Encefálica; Transplante de Órgãos; Comunicação.

\footnotetext{
Instituição

1 Departamento de Pós-Graduação em Psicologia Clínica e Cultura - Universidade de Brasília - Instituto de Psicologia - Brasília/DF

2 Curso de Psicologia da Universidade de Brasília - Instituto de Psicologia - Brasília/DF
}

\section{Correspondência}

Isabela Castelli

End.: SQN 110 - Bloco J - Apartamento 103 - Brasília/DF

Tel.: (61) 98166-8336

E-mail: castelli.isabela@gmail.com
Aceito em: 17/02/2016

\section{INTRODUÇÃO}

Com a evolução científica e tecnológica da Medicina, o conceito de morte, que, até então, era fundamentado na prática clínica pela constatação da parada irreversível das funções cardiorrespiratórias, passou a ser, também, da esfera da neurologia, com a necessidade do reconhecimento da cessação das funções cerebrais, fundamentada pelo conceito de morte encefálica (ME). ${ }^{1-2}$

No Brasil, o diagnóstico de ME é regulamentado pela Resolução do Conselho Federal de Medicina (CFM) $\mathrm{n}^{\circ}$ 1480, de 08 de agosto de $1997 .{ }^{3}$ Nesta, o diagnóstico deve ser realizado "considerando que a parada total e irreversível das funções encefálicas equivale à morte". ${ }^{3}$ Ainda de acordo com tal Resolução, o diagnóstico deve ser embasado por dois exames clínicos e um complementar, a serem realizados em intervalos de tempo variáveis, dependendo da idade do potencial doador. 
Atendida a Resolução do CFM e confirmado o diagnóstico de morte encefálica do paciente, inicia-se uma nova fase de cuidados: a manutenção hemodinâmica do paciente, agora designado de 'potencial doador'. Esses procedimentos - diagnóstico e manutenção - são descritos como potencialmente estressantes, uma vez que estão intimamente relacionados a um conjunto estruturado de ações que podem levar ao sucesso de um futuro transplante. ${ }^{4}$

O atendimento à Resolução No 1480 do $\mathrm{CFM}^{3}$ ajudou a operacionalizar, no Brasil, a mais importante modalidade de transplante de órgãos e tecidos, denominada post mortem, aquele com doador falecido. Dados do RBT 5 destacam que $82,6 \%$ do total de transplantes ocorridos no país, no período de janeiro a junho de 2015, por exemplo, utilizaram essa modalidade.

Além do CFM, a Portaria do Ministério da Saúde No 2.600, de 21 de outubro de 20096, aprovou a regulamentação técnica do Sistema Nacional de Transplantes, determinando a criação das Comissões Intra-Hospitalares de Doação de Órgãos e Tecidos para Transplante (CIHDOTTs), e definindo, ainda, que um sistema de Organização de Procura de Órgãos (OPO) pode, eventualmente, exercer função de CIHDOTT no estabelecimento de saúde em que estiver sediada.

Dessa forma, as principais funções da CIHDOTT/OPO são: (a) articular-se com a Central de Notificação, Captação e Doação de Órgãos (CNCDO) para organizar o processo de captação e doação de órgãos; (b) detectar pacientes que sejam classificados como potenciais doadores de órgãos e tecidos no hospital; e (c) possibilitar o diagnóstico de morte encefálica. ${ }^{6}$

Dada a natureza das atribuições administrativas e o contexto potencial de luto e perda que permeia a execução das ações da CIHDOTT, essenciais à identificação de potenciais doadores, supõe-se que as funções, mencionadas à CIHDOTT, sejam potencialmente produtoras de estresse a seus membros. Alguns autores, por exemplo, referem que equipes que trabalham com pacientes em ME percebem a tarefa com grande responsabilidade, num ambiente "onde nada pode dar errado". ${ }^{7}$ Nesse contexto, os profissionais devem vivenciar, com frequência, uma dicotomia de conceitos de vida e morte: a vitalidade dos órgãos que podem ser transplantados e salvar vidas de outras pessoas contrasta com o diagnóstico, irreversível, de morte encefálica e perda da vida de um ser humano. . $^{8-11}$

Uma tarefa essencial e determinante do sucesso das atribuições da CIHDOTT/OPO é realizar a entrevista com familiares do paciente com diagnóstico de ME, para avaliação e busca do consentimento à doação de órgãos e tecidos. Nesse momento, autores destacam a necessidade de a equipe profissional estar preparada para esclarecer dúvidas e enfrentar uma diversidade de potenciais reações emocionais por parte da família. ${ }^{4,12-14}$ Considerando-se que essa é uma das situações mais estressantes para os profissionais de saúde, ${ }^{9} 0$ objetivo do presente artigo foi analisar a percepção de profissionais de uma equipe de OPO, acerca de suas atividades de identificação de potenciais doadores e de comunicação com familiares. Destaca-se a pretensão de levantar quais momentos eram percebidos como mais desafiadores e de que forma a equipe se organizava para lidar com as tarefas que Ihes eram apresentadas.

\section{MÉTODO}

Foram identificados e entrevistados os nove profissionais da equipe de OPO do Hospital de Base do Distrito Federal (HBDF), maior unidade hospitalar, de atenção terciária, da Secretaria de Estado de Saúde do Distrito Federal. Dentre as 14 questões que compunham o roteiro padrão e semiestruturado de entrevista, elaborado especialmente para este estudo, o presente trabalho analisa os conteúdos de respostas de três questões: (a) "Considere que estamos no momento da entrevista com os familiares de um(a) potencial doador(a). Explique como você aborda a família"; (b) "Qual parte do seu trabalho você considera mais difícil e porquê"; e (c) "Qual parte do seu trabalho você considera mais prazerosa e porquê".

Todos os participantes foram convidados a participar da pesquisa, tendo acesso aos objetivos e justificativas do estudo e, caso aceitassem, assinariam o Termo de Consentimento Livre e Esclarecido (TCLE). As entrevistas individuais, agendadas conforme a disponibilidade de cada membro da equipe, foram gravadas em áudio, com o consentimento formal dos envolvidos, e transcritas na íntegra. Posteriormente, os autores realizaram análise de conteúdo das transcrições, elaborando categorias, por funcionalidade temática, cobrindo toda a amplitude de temas, conteúdos e variáveis abordadas.

Para o presente artigo, realizou-se um recorte da análise de conteúdo, evidenciando as categorias que permitiam reconhecer a percepção da experiência emocional dos entrevistados a partir das tarefas que executam, assim como dificuldades e prazeres que percebem no trabalho. Para tanto, três categorias temáticas foram geradas e analisadas: (a) Carga emocional atrelada à tarefa; (b) Considerações sobre a morte; e (c) Foco no receptor.

Em conformidade com a Resolução 466/2012 do Conselho Nacional de Saúde,$^{15}$ o projeto de pesquisa foi submetido ao Comitê de Ética em Pesquisa da Secretaria de Estado de Saúde do Distrito Federal, sob CAAE 53538716.5.0000.5553, tendo sido aprovado pelo parecer número 1.440 .623 . 


\section{RESULTADOS}

Para fins de organização desta seção de resultados, os profissionais são referidos pela letra maiúscula $P$, seguida de um número, designado aleatoriamente a cada um (P1, P2 ...), a fim de manter preservadas suas identificações.

\section{Carga emocional atrelada à tarefa}

Nessa categoria, referida por quatro dos nove profissionais, os entrevistados referem conteúdos de natureza afetiva, que evocam reações comportamentais, ilustradas pelas verbalizações a seguir.

(a parte) mais difícil, pra mim, é o familiar chorando, à beira do leito, pedindo para o outro voltar. Isso é o pior. Então, assim, me esgota. No fim do dia, é como se eu tivesse carregado um elefante (P1).

É, assim... porque você não quer chorar na frente da família, você não quer ter uma reação. Poxa, a família já está sofrendo e ainda tem que te aturar, né? (P2).

\section{Considerações sobre a morte}

Nessa categoria, com conteúdo referido em quatro entrevistas, os profissionais expressam suas reflexões sobre a morte e as implicações de estarem inseridos em uma área de atuação em que o serviço a ser executado depende, necessariamente, da morte de outras pessoas. Exemplos dessa categoria temática podem ser contemplados a seguir.

(reproduz a fala de colegas) 'não, nenhum? Poxa vida, ninguém? '. Aí, eu fazia a minha análise, olhava e pensava, será que ela ficaria satisfeita se eu voltasse 'aham! Seu filho tá lá!'. Porque é destoante, né? Tipo assim, eu fico feliz quando acho uma pessoa morrendo? (P1).

A todo momento você vê, seja jovem, adulto, rico, pobre, bandido, bonzinho, né? Assim, vai chegar uma hora, né, a morte (P3).

\section{Foco no receptor}

Essa categoria foi referida no discurso dos nove entrevistados. Quando foram solicitados a comentar aspectos prazerosos do serviço, todos os profissionais ressaltaram os receptores, de órgãos e tecidos, e a possibilidade de salvar vidas como momentos de prazer. Os exemplos, a seguir, ilustram esta temática.

É quando esse potencial doador, a família dele, mesmo com essa perda, com toda essa dor, ainda tem esse grande amor, né, de estar podendo salvar outras vidas (P4).
O mais prazeroso, realmente, é quando a gente consegue fechar o protocolo, né? Embora isso não seja o melhor para a familia, mas a gente executa o nosso trabalho ali. É.... fecha o protocolo, a família entende a situação, né? $E$ a gente consegue a doação para ajudar a salvar outras vidas. Isso é mais prazeroso. (P5).

\section{DISCUSSÃO}

Os dados apresentados neste estudo são corroborados pela literatura. Destacam os diversos obstáculos encontrados pela equipe de enfermagem responsável pelo cuidado dos pacientes que são potencias doadores e suas famílias. Os autores ressaltam a falta de habilidade para a comunicação de más notícias, o despreparo para lidar com reações emocionais de familiares em momento de perda e dificuldades das famílias para compreenderem o diagnóstico de ME. ${ }^{14}$ Acreditamos que esses são alguns fatores que contribuem para que os profissionais percebam o trabalho como exaustivo, conforme as verbalizações referidas na seção de Resultados.

O contato com os familiares e, especialmente, a entrevista, é percebida como o momento mais delicado pelos profissionais. Depreende-se, pelos trechos selecionados, a cobrança que os profissionais percebem no contato com os familiares de um potencial doador, sendo respaldado por estudo onde enfermeiros de uma equipe de OPO, do estado de São Paulo, relataram a entrevista familiar como um "processo que envolve muito mais o emocional, tanto do entrevistador, quanto da família que está sendo entrevistada". ${ }^{16}$

Em relação às considerações sobre o fim da vida, os autores descrevem que os profissionais tendem a se sentir ameaçados, nas situações em que se identificam com o paciente em ME, por temerem a própria morte ou a morte de pessoas próximas. ${ }^{10,11,17,18}$ Discute-se, ainda, a resistência por parte dos profissionais, em iniciar 0 protocolo de $\mathrm{ME}$, sugerindo dificuldades em lidar com a morte. ${ }^{8}$

Observa-se que a dificuldade para lidar com a morte constitui uma característica típica da nossa sociedade..$^{19}$ Acreditamos que essa situação esteja, em parte, relacionada à dificuldade de compreender a ME como equivalente à morte, e, ainda, como uma resposta ao tabu de evitarmos falar abertamente sobre questões acerca da finitude.

Levanta-se a hipótese de que, a partir das verbalizações dos participantes, os profissionais já puderam refletir diversas vezes sobre as questões da finitude subsidiados pelas situações típicas (de ME) do trabalho. 
Observações semelhantes também foram apontadas na literatura. ${ }^{4} \mathrm{Um}$ estudo com enfermeiros de uma equipe de captação de órgãos evidencia que refletir sobre sua própria finitude a partir do contato com um potencial doador é um fator altamente estressante. A autora aponta a necessidade de acompanhamento psicológico desses profissionais como alternativa para evitar ou reduzir o sofrimento psíquico. ${ }^{10}$

Os resultados obtidos neste estudo indicam a importância de preparar a equipe de saúde para o processo de morte, a fim de minimizar o sofrimento dos profissionais envolvidos com o cuidado e manejo do paciente em ME. Outros estudos ${ }^{20,10}$ apontam sentimento de insegurança, sofrimento e dor no discurso de profissionais envolvidos nos cuidados de pacientes em ME.

De forma complementar, discute-se que os profissionais de saúde ainda tendem a se sentir despreparados em situações de perda e crise. Esses autores acreditam que, ao questionar a família sobre uma possível doação de órgãos, o profissional torna-se consciente de suas próprias vulnerabilidades e finitude. ${ }^{14}$

Os dados obtidos reforçam a necessidade de psicólogo(s) como membros efetivos nas equipes envolvidas com a captação de órgãos e tecidos para transplante. Dentre as possibilidades de atuação desse profissional, além de promover suporte emocional para a família de potenciais doadores, poderiam desenvolver atividades psicoeducativas para as equipes de saúde, proporcionando espaços de discussão e reflexão sobre as questões relativas à morte e ao morrer. Ademais, o psicólogo, no contexto de doação de órgãos para transplante, poderia possibilitar espaços de escuta, facilitando a elaboração de questões que exigem maior atenção por parte dos profissionais.

Autores ${ }^{11}$ discutem, ainda, a percepção de fracasso dos profissionais, nos casos de confirmação de ME. Para os autores do presente estudo, isso reforça o modelo biomédico, onde a cura é o objetivo, em detrimento do cuidado. Supomos, então, que o foco nos receptores vai justamente ao encontro dessa linha de pensamento: em lugar da frustração de não ter podido curar um paciente em ME, o foco é deslocado para aqueles que podem beneficiar-se pela doação de órgãos. Essa perspectiva também é referida por outros autores. ${ }^{10,13,14,20}$
Achados semelhantes aos referidos neste estudo destacam o quanto o foco nos receptores está presente no discurso de equipes da OPO, a partir da verbalização de um profissional: "o significado de fazer uma entrevista para solicitar a doação é a questão de salvar vidas". ${ }^{16}$

Observou-se, pelos dados obtidos, que o foco nos receptores é, por vezes, abordado na entrevista familiar. Outros autores também observam que, na tentativa de obter consentimento para a doação, o profissional acaba sugerindo que há 'sentido transcendental' na doação, transformando a vida de outras pessoas que precisam dos órgãos. ${ }^{4,14,16,17}$

A literatura aponta, ainda, que os profissionais envolvidos com a captação de órgãos concebem a doação de órgãos como um "ato de coragem e solidariedade" por parte da família que, apesar da dor do luto, consegue desprender-se do corpo. ${ }^{10}$

Acreditamos que o foco nos receptores caracteriza um modelo de enfrentamento baseado no problema, por parte da equipe de saúde. Apesar de tais dados serem corroborados pela literatura, ${ }^{13,20}$ reforçamos que essa estratégia não deve ser utilizada para o convencimento da família que passa pela experiência de decidir, ou não, sobre a doação de órgãos para transplante, mas numa perspectiva de produzir benefícios à manutenção da vida de outras pessoas que também estão em processos de sofrimento, físico e psicológico, pela necessidade de transplantes de órgãos e tecidos.

\section{CONCLUSÃO}

Depreende-se que os dados apresentados estão em conformidade com a literatura disponível. Dessa forma, os resultados aqui discutidos corroboram a necessidade de treinamento adequado aos profissionais integrantes das CIHDOTT, bem como a importância de desenvolver espaço de escuta e troca entre pares, a fim de prestar melhor apoio às famílias atendidas. Aponta-se como principal limitação do estudo todos os participantes serem de uma mesma equipe, sendo, assim, um recorte muito específico. 


\section{ABSTRACT}

Based on the regulation of the National Transplantation System upon the creation of the Intra Hospital Commission for Organ and Tissue Donation for Transplant (CIHDOTT) teams, a new field was structured for health professionals. Its main tasks are to organize the organ donation and transplantation process; to detect patients classified as potential donors and ask the family of the patient for their willingness for the organs donation for transplantation. Purpose: Having in mind that working in hospitals is a potentially stressful activity, and within the context described above aggravated by the direct contact with the death and finitude, a group of nine healthcare professionals from a public hospital in Brasília was interviewed in order to understand their experience on the work. Method: The healthcare professionals were invited to participate in the present study, which was based on the semi-structured interview method. The interviews were audio recorded and fully transcribed. Subsequently, the analysis of the discourse was carried out with the elaboration of the thematic axes. Results: In the present text, we highlight the following categories: emotional charge, considerations on the death and focus on the recipient. Conclusion: The data discussed here, in accordance with the current literature emphasizes the need for an adequate training of the CIHDOTT healthcare teams, as well as the importance of spaces for hearing and peer exchanges.

Keywords: Tissue and Organ Procurement; Brain Death; Organ Transplantation; Communication.

\section{REFERENCES}

1. Hadders $\mathrm{H}$, Alnaes $\mathrm{AH}$. Enacting death: contested practices in the organ donation clinic. Nursing Inquiry 2013; 20(3): 245-55.

2. Slade J, Lovasik D. Understanding brain death criteria. Nursing 2002;32(12):68-9.

3. Critérios de morte encefálica. Diário Oficial da União, Seção 21: 18227-18228 (1997)

4. Cavalcante LP, Ramos IC, Araújo MAM, Alves MDS, Braga VAB. Cuidados de enfermagem ao paciente em morte encefálica e potencial doador de órgãos. Acta Paulista de Enfermagem 2014;27(6):567-672.

5. REGISTRO BRASILEIRO DE TRANSPLANTES. Dados numéricos da doação de órgãos e transplantes realizados por estado e instituição no período: janeiro/junho, 2015. Revista da Associação Brasileira de Transplantes de Órgãos 2015;21(2):1-29.

6. Regulamento Técnico do Sistema Nacional de Transplantes. Diário Oficial da União, Seção 1: 77-118 (2009).

7. Pestana AL, Santos JLG, Erdmann RH, Silva ELS, Erdmann AL. Pensamento Lean e cuidado ao paciente em morte encefálica no processo de doação de órgãos. Revista Escola de Enfermagem da USP 2013;47(1):258-64.

8. Araújo MN, Massarollo MCKB. Conflitos éticos vivenciados por enfermeiros no processo de doação de órgãos. Acta Paulista de Enfermagem 2014;27(3):15-220.

9. Guido LA, Linch GFC, Andolhe R, Conegatto CC, Tonini CC. Estressores na assistência de enfermagem ao potencial doador de órgãos. Revista Latino-Americana de Enfermagem 2009;17(6):1-7.

10. Lima AAF. Doação de órgãos para transplante: conflitos éticos na percepção do profissional. O Mundo da Saúde 2012;36(1):27-33.
11. Souza SS, Borenstein MS, Silva DMGV, Souza SS, Carvalho JB. Situations of stress experienced by nursing staff in the care of potential organ donor. Journal of Research Fundamental Care Online 2013;5(3):42-52.

12. Cappellaro J, Silveira RS, Lunardi VL, Corrêa LVO, Sanchez ML, Saioron I. Comissão Intra-Hospitalar de Doação de Órgãos e Tecidos para Transplante: questões éticas. Revisa Rene 2014;15(6):949-56.

13. Moraes EL, Santos MJ, Merighi MAB, Massarollo MCKB. Vivência dos enfermeiros no processo de doação de órgãos e tecidos para transplante. Revista Latino-Americana de Enfermagem 2014;22(2):226-33.

14. Moraes EL, Neves FF, Santos MJ, Merighi MAB, Massarollo MCKB. Experiências e expectativas de enfermeiros no cuidado ao doador de órgãos e à sua família. Revista da Escola de Enfermagem da USP 2015; 49(2): 129-135.

15.Resolução 466 do Conselho Nacional de Saúde. Diário Oficial da Únião, Seção 1. (2012).

16.Santos MJ, Massarollo MCKB, Moraes EL. Entrevista familiar no processo de doação de órgãos e tecidos para transplante. Acta Paulista de Enfermagem 2012;25(5):788-94.

17.Monforte-Royo C, Roqué MV. The organ donation process: A humanist perspective based on the experience of nursing care. Nursing Philosophy 2012;13:295-301.

18. Ronayne C. A phenomenological study to understand the experiences of nurses with regard to brainstem death. Intensive and Critical Care Nursing 2009;25:90-98.

19.Quintana AM, Arpini DM. Doação de órgãos: possíveis elementos de resistência e aceitação. Boletim de Psicologia 2009;59(130):91-102.

20.Lemes MMDD, Bastos MAR. Os cuidados de manutenção dos potenciais doadores de órgãos: estudo etnográfico sobre a vivência da equipe de enfermagem. Revista LatinoAmericana de Enfermagem 2007;15(5):1-7. 